MATEC Web of Conferences 3, 01018 (2013)

DOI: $10.1051 /$ matecconf/20130301018

(c) Owned by the authors, published by EDP Sciences, 2013

\title{
The thermodynamics of alcohols-hydrocarbons mixtures
}

\author{
R. Privat ${ }^{1}$, J.-N. Jaubert ${ }^{1}$, and M. Molière ${ }^{2}$ \\ ${ }^{1}$ Laboratoire Réactions et Génie des Procédés (LRGP), Université de Lorraine, Nancy 54000, France \\ ${ }^{2}$ GE Energy Products - Europe, 20 Avenue du Maréchal Juin , BP 379, 90007 Belfort Cedex, France
}

Alcohols/hydrocarbons blends represent important products in the industry and remarkable systems from the thermodynamic standpoint, especially in presence of traces of water. In automotive applications, ethanol is incorporated in increasing proportions into car fuel formulations for environmental and economic reasons.

From a thermodynamic viewpoint, the strongly polar nature of ethanol versus the rather apolar character of hydrocarbons makes the study of such blends particularly interesting in terms of vapor pressure and miscibility behavior.

A long term collaboration between GE EnergyEurope (Belfort, France) and the Thermodynamics Team of the LRGP laboratory (Nancy, France) has been conducted to improve the knowledge of these systems, using the UNIFAC thermodynamic theory. First, blends of anhydrous ethanol and naphtha class hydrocarbons have been studied in terms of volatility: a strong liquid/vapor non-ideality effect has been put in evidence and numerically characterized. In a further step, blends of hydrated ethanol and hydrocarbons featuring diverse compositions have been the matter of a thermodynamic modeling that confirmed the paramount role played by the moisture content of ethanol on the miscibility, using the Maximum Miscibility Temperature ("TMM") concept; this study also pointed out the non-negligible influence of the PONA data and sulfur species of the hydrocarbon cut. Later on, other alcohols namely methanol, isopropanol and n-butanol, that may play an important role in future "green fuel" formulations, were included in this study that showed an interesting chain length effect.

Recently, the team has started a study of the effect of biodiesel additions on the TMM of hydrated alcoholhydrocarbon mixtures.

This paper summarizes the methodology and the results of the multi-step, collaborative modeling study developed in the field of ethanol/hydrocarbon thermodynamics.

\section{Introduction}

In recent years, the quest for sustainable primary energies has increased the potential interest of biogenic/fossil fuels mixes. In this context, light alcohols are often used as gasoline extenders to both partly substitute for hydrocarbon car fuels and increase their octane number (RON) while improving vehicle emissions. Industrial alcohols often contain a non-negligible amount of water (that can reach $10 \%$ in mass). From a thermodynamic point of view, the addition of an industrial alcohol (even in small quantities) to a gasoline or a gasoil strongly impacts on all phase equilibria.

GE and the thermodynamic team of the LRGP are conducting a collaborative, multi-year program aimed at studying these systems with a special emphasis placed on the vapor pressure and the miscibility behaviour. In 2009, the team carried out a first study devoted to the change in vapor pressure caused by the incorporation of anhydrous ethanol into a naphtha cut taken as surrogate for a commercial gasoline. In 2010, the thematic of the alcohols/gasoil miscibility was tackled and led to study the influence of the type of alcohol and its water content on its miscibility with selected gasoil cuts featuring various compositions (paraffin/ aromatics/ naphthenes distribution; sulphur compounds). Since the openliterature contains very few experimental data in this area, the strategy has been in favor of a theoretical approach.

Four industrial alcohols (methanol, ethanol, isopropanol or 1-butanol) featuring various water contents and four commercial gasoil with defined hydrocarbon distributions were included in this study.

\section{Vapor pressure of ethanol-naphtha blends}

The theoretical approach is based on the 1978 version of the Peng and Robinson equation of state [1], noted "PR78" in this paper. More information on the theoretical model is available in [2].

Figure 1 shows a plot of the vapour pressure data computed for blends containing variable proportions of anhydrous ethanol and a naphtha consisting in $18 \% \mathrm{n}$ hexane and $82 \%$ n-heptane by weight. 


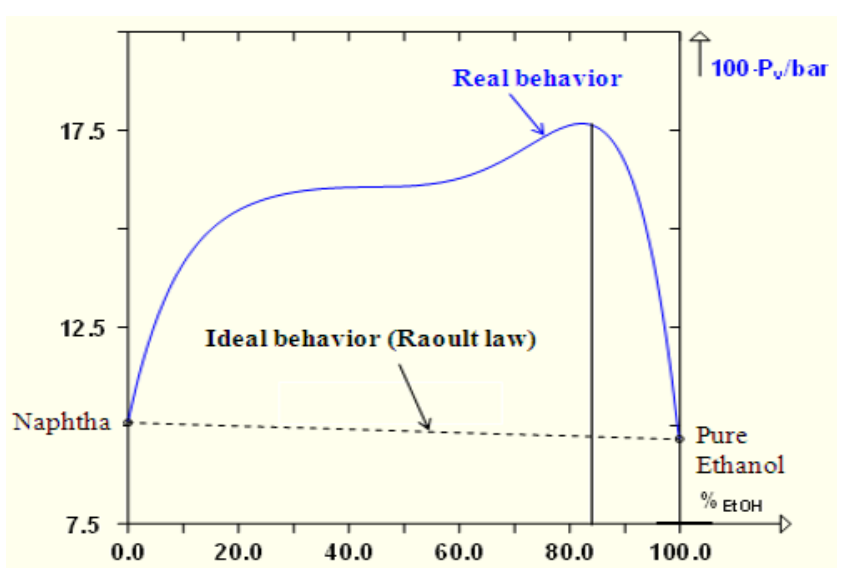

Figure 1. Vapor pressure deviation from ideality for a naphtha/ethanol blend.
This figure demonstrates the highly non-ideal behavior of these blends: for instance, for a blend containing $17 \%$ ethanol, a calculation assuming an ideal behaviour (Raoult's law) would lead to undervalue the vapour pressure by $51 \%$ (table 1 ).

These results are very important from a safety standpoint since the Lower and Upper Flammability Limits depend on the vapour pressure; they are also relevant for the selection of the right naphtha cuts when one wishes to prepare ethanol/gasolines blends having suitable volatility for cars (e.g. "E10").

Table 1. Vapor pressure of tanks containing (i) naphtha, (ii) ethanol and (iii) a given naptha-ethanol blend $\left(27^{\circ} \mathrm{C}, 70 \%\right.$ full tank $)$.

\begin{tabular}{|c|c|c|c|c|c|}
\hline \multirow[b]{2}{*}{ Liquid (\% mass) } & \multirow{2}{*}{$\begin{array}{l}\text { (i) Naphtha: } \\
\left(18 \% \mathrm{C}_{6}+\right. \\
\left.82 \% \mathrm{C}_{7}\right)\end{array}$} & \multirow{2}{*}{$\begin{array}{c}\text { (ii) } 100 \% \\
\mathrm{EtOH}\end{array}$} & \multicolumn{3}{|c|}{ (iii) $83 \%$ napththa $+17 \%$ EtOH } \\
\hline & & & $\begin{array}{c}\text { Real } \\
\text { (computed) }\end{array}$ & $\begin{array}{c}\text { Ideality } \\
\text { hypothesis }\end{array}$ & $\begin{array}{l}\text { Relative } \\
\text { difference }\end{array}$ \\
\hline Vapor pressure (mbar) & 101.3 & 99.6 & 152 & 101 & $51 \%$ \\
\hline
\end{tabular}

\section{Alcohol-gasoil miscibility study}

In this paper, we will use a pseudo-binary system made by the hydrocarbon mixture constituting the gasoil, on one hand, and the alcohol/water mixture (also called "hydrated alcohol" or "industrial alcohol"), on another hand. To characterize the miscibility behaviour of such gasoil/alcohol/water systems, it is convenient to access to the so-called Minimum Miscibility Temperature ("MMT") which is the lowest temperature at which the fluids are fully miscible, regardless of the proportion of industrial alcohol. For any temperature below the MMT, addition of industrial alcohol to the gasoil may give rise to two liquid phases in equilibrium while, for any temperature above the MMT, the mixture cannot unmix anymore, as illustrated in figure 2 .

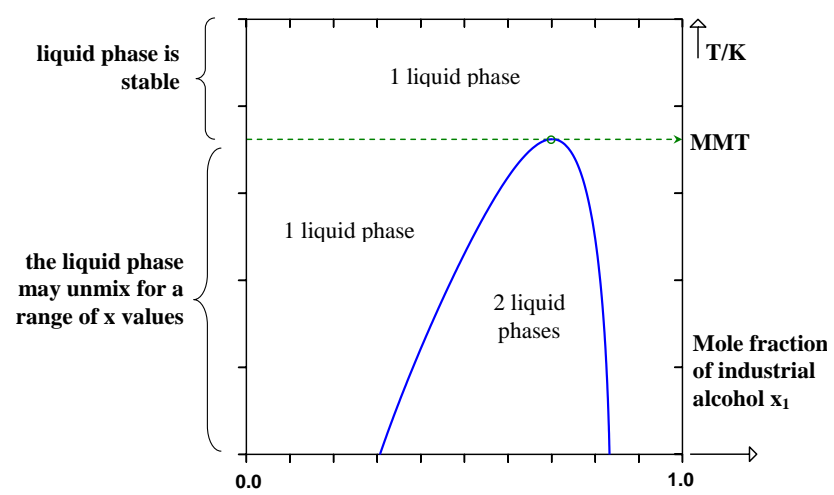

Figure 2. Pseudo-binary phase diagram for a mixture of gasoil and industrial alcohol. The bell is the boundary between the single liquid and the two-liquid fields (saturation curve). MMT is the summit of the saturation curve.
The sketch of figure 2 has large commonalities with classical liquid-liquid phase diagrams of binary systems in which (i) the maximum of the saturation curve is actually a liquid-liquid critical point (and is called UCST for "upper critical solution temperature", instead of MMT) and (ii) it is possible to draw a horizontal tie-line at a given temperature. However, since the pseudo-binary gasoil/industrial alcohol systems involve many compounds, it is no longer possible to draw horizontal tie-lines; in addition, the maximum of the saturation curve is not a critical point anymore (a critical point may exist anywhere on the saturation curve). The openliterature is very poor in MMT data for gasoil/industrial alcohols systems. For this reason, we decided to use an efficient predictive thermodynamic model, called "UNIFAC" for representing the behavior of the fluids of interest. This model relies on the group-contribution concept and is able to account for the effects of: (i) the nature of the alcohol and (ii) additions of small amounts of water in the alcohol. In studying four gasoils (noted GO1, GO2, GO3 and GO4) having different compositions, it is possible to investigate the influence of the paraffinic, aromatic, naphthenic and sulphur contents. The rough compositions of these four gasoils are given table 1. As we will work with condensed liquid phases, the pressure effect will be neglected throughout this study. 
Table 2. Compositions of the four studied gasoils

\begin{tabular}{|c|c|c|c|c|}
\hline Compounds & GO1 & GO2 & GO3 & GO4 \\
\hline Paraffinic & $16 \%$ & $10.5 \%$ & $84 \%$ & $90 \%$ \\
\hline Aromatic & $84 \%$ & $82 \%$ & $16 \%$ & $8 \%$ \\
\hline Naphthenic & 0 & 0 & 0 & $2 \%$ \\
\hline Sulphur & - & $7.5 \%$ & - & - \\
\hline
\end{tabular}

\section{The Group-Contribution concept}

\subsection{General aspects}

The group-contribution (GC) approach is a relatively recent concept [1-17] which originally aimed at predicting the physical properties of pure molecules starting from their chemical structures. The application of the GC concept to mixtures is actually an extension of the GC concept for single molecules [3, 18]. The basic idea of any group-contribution method is that, whereas there are thousands of chemical molecules, the number of functional groups that constitute them is very limited. Assuming that a physical property of a fluid is the sum of contributions made by the molecule's functional groups, one can use a GC method to correlate the properties of a very large number of fluids based on a much smaller number of parameters. These GC parameters characterize the contributions of individual groups in the properties. In this paper, a predictive thermodynamic model based on the GC concept, named UNIFAC, is used for calculating liquid-liquid phase equilibria of complex gasoil/alcohol/water mixtures.

\subsection{Outlines of the UNIFAC method}

This model enables the estimation of the complete sets of activity coefficients of all the components in a mixture, without fitting any model parameter from liquid-liquid experimental data. The mere knowledge of the chemical structure of all the compounds in the mixture is enough to predict phase equilibria. Based on the mathematical formulation of the non-predictive UNIQUAC model, the UNIFAC model can be seen as a predictive version of this last model. The UNIQUAC equation often gives good representations of vapor-liquid and liquid-liquid equilibria for binary and multicomponent mixtures containing a variety of non-electrolytes, such as for instance hydrocarbons and alcohols. The molecular activity coefficient is break down into two parts: one part provides the contribution due to differences in molecular size and shape ("the combinatorial part"), and the other provides the contribution due to molecular interactions ("the residual part"). In a multicomponent mixture, the UNIFAC equation for the activity coefficient of component "i" writes:

$\ln \gamma_{i}=\ln \gamma_{i}^{\text {comb }}+\ln \gamma_{i}^{\text {res }}$
The calculation of $\ln \gamma_{i}^{\text {res }}$ requires the knowledge of energy group-interaction parameters $\mathrm{a}_{\mathrm{mn}}$, the values of which were estimated from phase equilibrium data regression by Fredenslund et al. [18]. Note however that some $\mathrm{a}_{\mathrm{mn}}$ values were refitted by this team in previous works (GT 2010-22126 and GT2011-45896) for selected chemical groups involved in gasoil/alcohol mixtures; more details about the UNIFAC model are available in these references.

\section{Liquid-liquid phase diagrams for multicomponent systems}

Due to the high number of compounds contained in gasoil/industrial alcohol mixtures (between 30 and 50 in the present case), the calculation of the saturation curve is a much more complicated and time-consuming task than for actual binary systems. This section is thus devoted to explain the options used to perform fast and reliable calculations of saturation curves in a reasonable time.

\subsection{Direct calculation of the saturation curve}

In this section, the gasoil composition is assumed to be known. Let us define a system resulting from the mixing of a given amount of industrial alcohol (fully defined in terms of composition) with a given amount of gasoil. The overall mole fraction vector $\mathbf{z}$ of such a system is thus completely characterized; let us also denote $\mathbf{z}_{\text {alcohol }}$, the overall composition of the industrial alcohol. The system is a single, stable liquid phase at high temperature and gives rise to a liquid-liquid equilibrium at low temperature. The saturation point is defined as the transition state between the single-liquid state and the liquid-liquid equilibrium state. Let us denote $T^{*}$ the saturation temperature. The calculation of a saturation point (i.e. a point of the saturation curve) is illustrated in figure 3 .

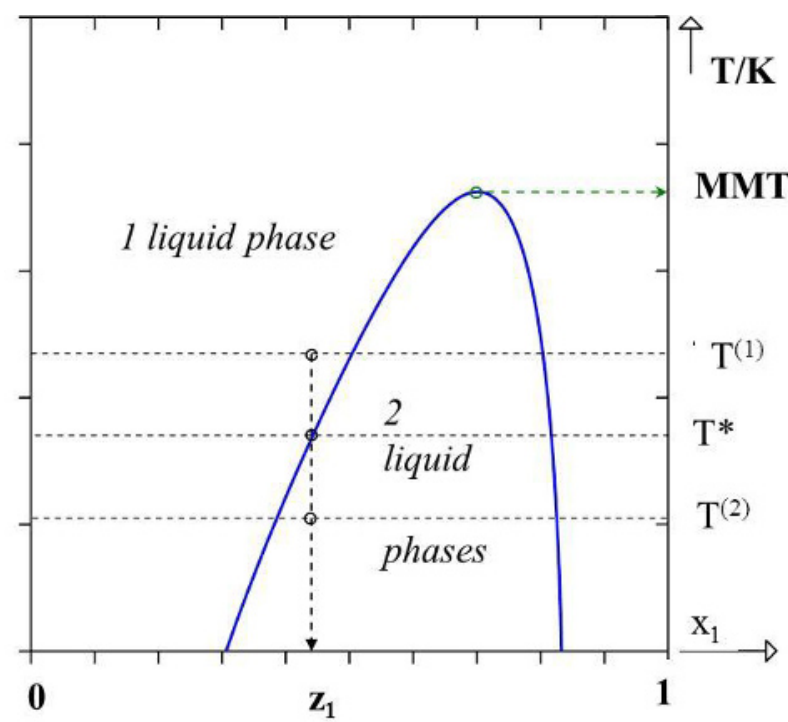

Figure 3. Direct calculation of the saturation point at a fixed overall composition $\mathrm{z}$. 
A saturation point corresponds to two liquid phases in equilibrium, the first one having a known composition $\mathbf{z}$ and the second one having an unknown composition $\mathbf{x}$. The unknown variables $\mathrm{T}^{*}$ and $\mathbf{x}$ can be determined by solving the following set of equations:

$\left\{\begin{array}{l}a_{i}\left(T^{*}, z\right)=a_{i}\left(T^{*}, \mathbf{x}\right), \text { for all } i \in 1 ; \ldots ; N \\ \sum_{i=1}^{N} x_{i}=1\end{array}\right.$

where $\mathbf{a}_{\mathbf{i}}$ is the activity of component " $\mathrm{i}$ " calculated from the UNIFAC model and $\mathrm{N}$ is the total number of compounds contained in the mixture. The first line of the equation set (2) is obtained by equating the chemical potential of component " $i$ " in the two liquid phases, which expresses the liquid-liquid equilibrium condition). The second line expresses the normalization of the molar fractions.

To facilitate the resolution of the equation set (2), one can rewrite it as an optimization problem, e.g.:

$\left\{\begin{array}{l}\underset{\mathrm{T}^{*}, \mathbf{x}}{\operatorname{Min}}\left[\mathrm{a}_{\mathrm{i}}\left(\mathrm{T}^{*}, \mathbf{z}\right)-\mathrm{a}_{\mathrm{i}}\left(\mathrm{T}^{*}, \mathbf{x}\right)\right]^{2} \\ \text { under the constraint } \sum_{\mathrm{i}=1}^{\mathrm{N}} \mathrm{x}_{\mathrm{i}}=1\end{array}\right.$

Doing so, classical optimization procedures (such as e.g. quasi-Newton methods) can be applied to determine $\mathrm{T}^{*}$ and $\mathbf{x}$. In the present case, the SLSQP (Sequential Least Squares Quadratic Programming), optimization algorithm was used and led generally to satisfactorily results. Of course, when drawing the complete saturation line, the calculation of a given saturation point can be easily initialized from variables $\mathrm{T}^{*}$ and $\mathbf{x}$ of the previous saturation point. However, the initialization procedure of the first calculated saturation point remains an entire problem. Despite generally satisfactory results, it was observed that the resolution of eq. (3) using the SLSQP procedure was likely to fail when:

- the saturation point to be calculated is very close to a liquid-liquid critical point (such that the two liquid phases in equilibrium have the same composition, i.e. $\mathrm{x}=\mathrm{z}$ )

- several liquid-liquid equilibria exist at a given overall composition $\mathbf{z}$; when this situation occurs, one liquid-liquid equilibria is declared stable (the one associated to the lowest Gibbs energy value) and the other ones are declared non-stable.

Each time a direct calculation of a saturation point failed, another procedure based on a flash algorithm calculation was run. Such a combination of these two procedures allowed us to successfully plot the saturation curves of all the considered gasoil/industrial alcohol systems within a reasonable time (less than 1 minute for each curve containing 150 points). Note that the flash algorithm can also be used to initialize the first calculated point of the saturation curve.

\subsection{Indirect calculation of the saturation curve using a flash-calculation based procedure}

A liquid-liquid flash calculation is a classical algorithm aimed at determining whether a multicomponent liquid mixture gives rise to a liquid-liquid equilibrium at a given temperature and overall composition $\mathbf{z}$. If so, the flash calculation provides the composition of the phases as well as their proportions. As illustrated in figure 4 , it is possible to use this kind of calculation to determine the saturation temperature $\mathrm{T}^{*}$.

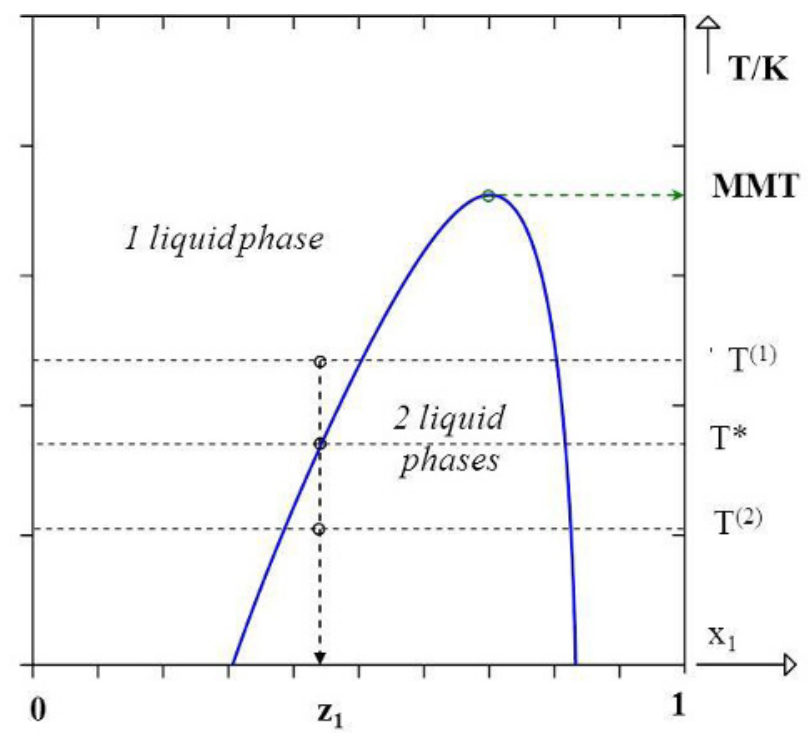

Figure 4. Indirect calculation of the saturation point at a fixed overall composition $\mathrm{z}$.

To do so, it is necessary to perform a series of flash calculations in order to determine two temperatures $T^{(1)}$ and $\mathrm{T}^{(2)}$ such that: $\mathrm{T}^{(2)}<\mathrm{T}^{*}<\mathrm{T}^{(1)}$ where $\mathrm{T}^{(1)}$ is a temperature at which the system consists of a single liquid phase and $\mathrm{T}^{(2)}$ is a temperature at which the system consists of two liquid phases in equilibrium.

The saturation temperature $\mathrm{T}^{*}$, which is the transition temperature between a 2-phase and a 1-phase system, can be accurately calculated using, for instance, a dichotomic procedure.

\subsection{Flash calculation}

Let us consider an $\mathrm{N}$-component system having an overall composition $\mathbf{z}$ and giving rise to a liquid-liquid equilibrium (the two liquid phases in equilibrium are denoted $\alpha$ and $\beta$ ). To perform a flash calculation, a set of $(2 \mathrm{~N}+2)$ equations has to be solved:

$$
\begin{cases}a_{i}\left(T, x_{\alpha}\right)=a_{i}\left(T, x_{\beta}\right), & \forall i \in 1 ; \ldots ; N \\ z_{i}=x_{i, \alpha} \tau_{\alpha}+x_{i, \beta} \tau_{\beta}, & \forall i \in 1 ; \ldots ; N \\ \sum_{i=1}^{N} x_{i, \alpha}=1 & \\ \sum_{i=1}^{N} x_{i, \beta}=1 & \end{cases}
$$


where $\tau_{\alpha}$ and $\tau_{\beta}$ are the proportions of the liquid phases $\alpha$ and $\beta$ and the compositions of these two liquid phases are noted $\mathrm{x}_{\alpha}$ and $\mathrm{x}_{\beta}$.

To solve the set of equations (4), the well-known Rice-Rachford procedure can be applied.

\section{6 influence of the alcohol and the water content on the MMT}

In this study, four real commercial gasoils (GO1, GO2, GO3 and GO4) were selected; their detailed compositions are given in table 3. These types of gasoils were taken because they contain different amounts of paraffinic, aromatic, naphthenic and sulphur compounds. The first gasoil (GO1) contains $84 \%$ of aromatic compounds, 16 $\%$ of paraffinic compounds and no sulphur species. GO2 is similar to GO1 but contains $7.5 \%$ of sulphur compounds. On the contrary, GO3 and GO4 contain large amounts of paraffinic compounds (more than $80 \%$ ), and small quantities of aromatics. GO4 has the particularity to contain a small amount of naphthenic hydrocarbons. It is thus possible to evaluate how these chemical families impact on the MMT value of gasoil/industrial alcohol mixtures.
The first task is the calculation of the liquid-liquid phase diagram using the UNIFAC model.

\subsection{Addition of four different industrial alcohols in gasoil G01}

The highest temperature at which the phase split occurs i.e. the MMT has been calculated. The corresponding phase diagrams are shown in figure 5 and the corresponding MMT are given in table 4.

Table 4. MMT values for gasoil GO1 mixed with the four alcohols having various $\mathrm{H} 2 \mathrm{O}$ contents.

\begin{tabular}{|c|c|c|c|c|}
\hline$\% \mathrm{H}_{2} \mathrm{O}$ (mass) & methanol & ethanol & isopropanol & butanol \\
\hline 1 & 244 & 33 & -18 & 0 \\
\hline 2 & 248 & 57 & 52 & 77 \\
\hline 3 & 254 & 90 & 107 & 138 \\
\hline 4 & 263 & 130 & 155 & 192 \\
\hline 6 & 295 & 211 & 244 & 292 \\
\hline 8 & 336 & 287 & 327 & 383 \\
\hline 10 & 386 & 361 & 406 & 471 \\
\hline
\end{tabular}
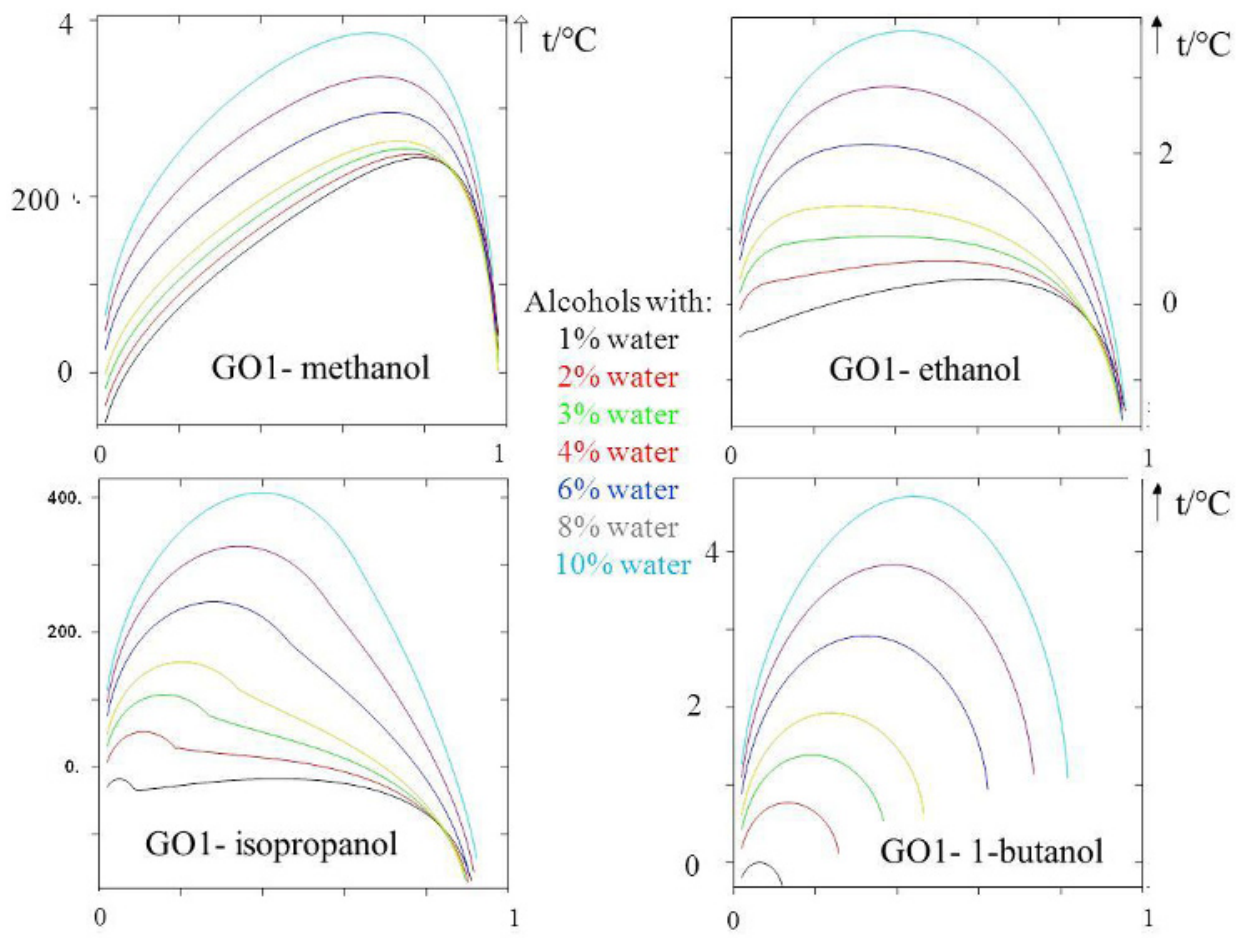

Figure 5. Phase diagrams for GO1 mixed with 4 alcohols containing from 1 to $10 \%$ water (in abscissa: mole fraction of hydrated alcohol).

For any alcohol content, one observes that:

- the MMT systematically increases with the proportion of water in the alcohol

- the heavier the alcohol, the stronger this increase; thus, when the water percent goes from 1 to $10 \%$, the MMT (in K) is multiplied by: 1.3 for the methanol;
2.1 for the ethanol; 2.7 for the isopropanol and for 1 butanol.

The changes of MMT with the alcohol mass water contents are represented in figure 6 . As it can be observed, the smallest MMT values are obtained with heavy alcohols having small water contents. 
Table 3. Speciated analyses of the four gasoils.

\begin{tabular}{|c|c|c|c|c|}
\hline Components & GO1 & GO2 & GO3 & GO4 \\
\hline 1,4-dimethyl benzene (para-xylene) & 1.0 & 1.0 & 0.9 & 0.7 \\
\hline 1-ethyl-3-methyl benzene & 2.6 & 3.0 & 4.2 & 1.9 \\
\hline 1,2,3-trimethyl benzene & 2.4 & 2.5 & 5.9 & 2.7 \\
\hline benzocyclopentane (indane) & 0.7 & 0.6 & & \\
\hline 1-methyl-1-propyl benzene & 0.7 & 0.6 & 1.2 & \\
\hline 4-ethyl-1,2-dimethyl benzene & 3.3 & 3.7 & 1.7 & 0.8 \\
\hline 1,2,4,5-tetramethyl benzene & 0.7 & 0.6 & & \\
\hline 1-methyl-4-(2-propenyl) benzene & 2.0 & 2.0 & & \\
\hline 1-methyl-1-butyl Benzene & 1.1 & 0.5 & & \\
\hline Naphthalene & 1.2 & 1.3 & 1.5 & \\
\hline 2,3-dihydro-1,2-dimethyl $1 \mathrm{H}$-indene & 3.3 & 3.4 & & 1.6 \\
\hline 1-methyl naphthalene & 7.0 & 8.6 & & \\
\hline 1-ethyl naphthalene & & 2.9 & & \\
\hline 1,2-dimethyl naphthalene & 17.6 & 18.4 & & \\
\hline 1,4-dihydro-1,4-methano naphthalene & 1.0 & 1.4 & & \\
\hline 1,3,6-trimethyl naphthalene & 15.7 & & & \\
\hline n-pentadecane & 1.0 & 2.1 & 4.78 & 7.3 \\
\hline fluorene & 1.0 & & & \\
\hline 1-methyl-1-ethyl naphthalene & 0.9 & 17.2 & & 0.8 \\
\hline 2-methyl biphenyle & 1.8 & 3.1 & & \\
\hline n-hexadecane & 1.4 & 2.2 & 3.3 & 6.5 \\
\hline 7-ethyl-1,4-diethyl azulene & 2.8 & 1.9 & & \\
\hline 2,2-dimethyl biphenyle & 4.6 & 4.1 & & \\
\hline n-heptadecane & 2.0 & 1.1 & & 4.0 \\
\hline phenanthrene & 2.9 & 1.2 & & \\
\hline n-octadecane & 2.2 & 0.8 & 2.1 & 4.65 \\
\hline 1-methyl phenanthrene & 7.9 & 1.7 & & \\
\hline n-nonadecane & 2.3 & 0.7 & 1.3 & 3.2 \\
\hline 9,10-dimethyl anthracene & 1.4 & & 1.1 & \\
\hline n-eicosane & 2.2 & 0.7 & 0.8 & 3.6 \\
\hline n-heneicosane & 2.1 & 0.6 & 0.6 & 3.2 \\
\hline n-docosane & 1.8 & 0.6 & 0.5 & 1.3 \\
\hline n-tricosane & 0.9 & 0.5 & 0.4 & 0.9 \\
\hline n-tetracosane (n-pentacosane) & 0.5 & 0.4 & $(0.3)$ & 0.9 \\
\hline 2,3-dihydro-1-methyl indene & & 0.6 & & \\
\hline para-diisopropyl benzene & & 0.5 & & \\
\hline n-octane & & & 6.25 & \\
\hline n-nonane & & & 16.6 & 13.8 \\
\hline n-decane & & & 8.5 & 4.85 \\
\hline n-undecane & & & 17.6 & 7.35 \\
\hline n-dodecane (n-tridecane) & & & & $9.8(8.6)$ \\
\hline n-tetradecane & & & 17.35 & 9.85 \\
\hline n-hexacosane - (n-heptacosane) & & & $0.3(0.3)$ & \\
\hline 1-methylethyl cyclohexane & & & & 0.6 \\
\hline octyl cyclohexane & & & & 0.6 \\
\hline decyl cyclohexane & & & & 0.5 \\
\hline benzothiophene & & 0.5 & & \\
\hline methyl benzothiophene & & 0.9 & & \\
\hline dimethyl benzothiophene & & 3.0 & & \\
\hline dibenzo thiophene & & 0.9 & & \\
\hline thioxanthene & & 1.7 & & \\
\hline
\end{tabular}




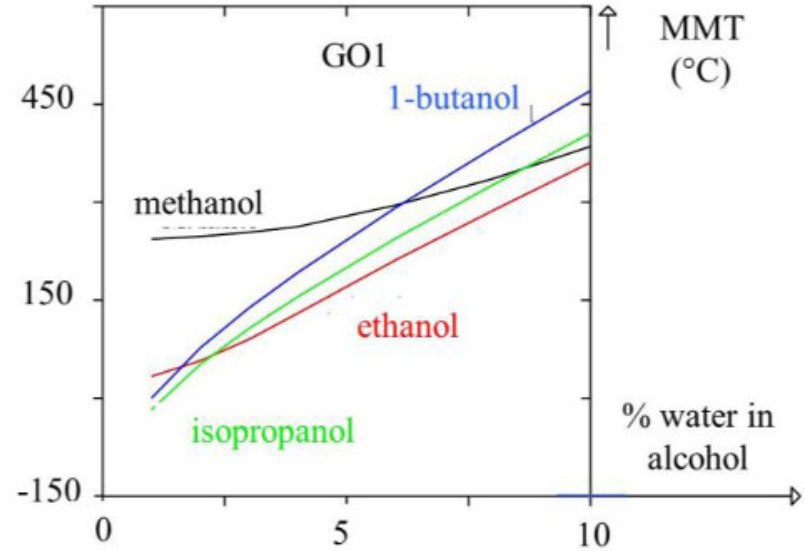

Figure 6. Change of the MMT of the four GO1/alcohols with the water content of the alcohol.

\subsection{Addition of four different industrial alcohols in gasoil GO2}

The MMT data are given in table 5 and the corresponding phase diagrams can be seen in figure 7 .

Table 5. MMT values for gasoil GO2 mixed with the four alcohols having various $\mathrm{H}_{2} \mathrm{O}$ contents.

\begin{tabular}{|c|c|c|c|c|}
\hline$\% \mathrm{H}_{2} \mathrm{O}$ (mass) & methanol & ethanol & isopropanol & butanol \\
\hline 1 & 272 & 56 & 0 & 7 \\
\hline 2 & 278 & 80 & 59 & 84 \\
\hline 3 & 283 & 109 & 114 & 146 \\
\hline 4 & 290 & 145 & 163 & 199 \\
\hline 6 & 321 & 223 & 252 & 298 \\
\hline 8 & 358 & 299 & 334 & 390 \\
\hline 10 & 405 & 373 & 414 & 478 \\
\hline
\end{tabular}
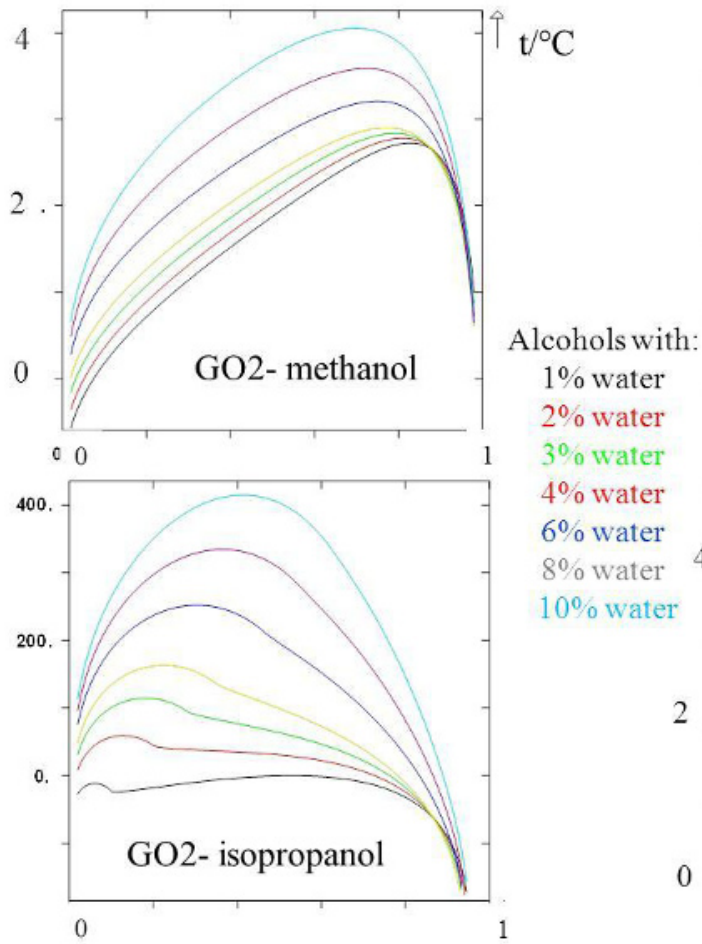

$4 \%$ water

$6 \%$ water

$8 \%$ water

$10 \%$ water

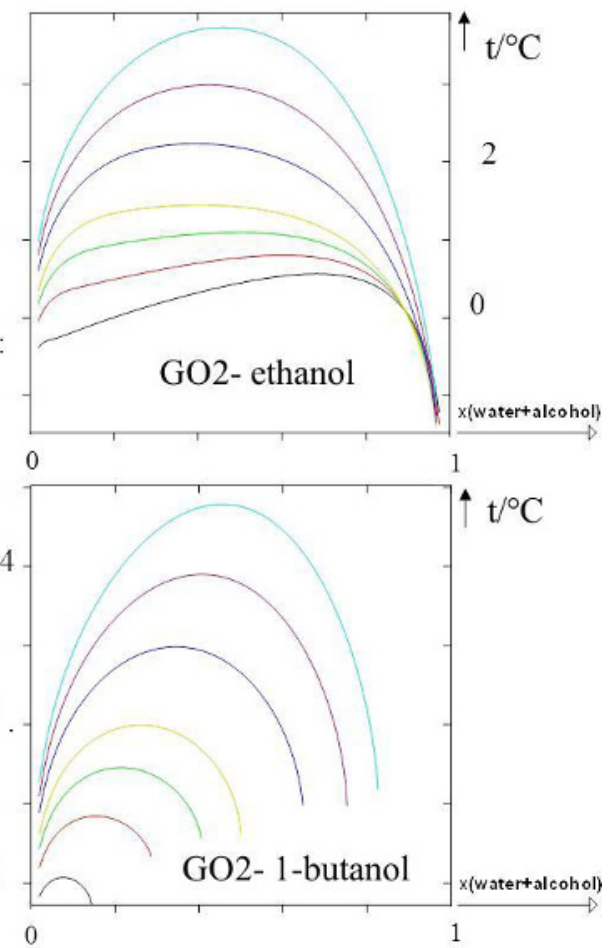

Figure 7. Phase diagrams for GO2 mixed with 4 alcohols containing from 1 to $10 \%$ water (in abscissa: mole fraction of hydrated alcohol). 


\subsection{Addition of four different industrial alcohols in gasoil GO3}

The phase diagrams can be seen in figures 9 and 10 and the corresponding MMT are given in table 6.

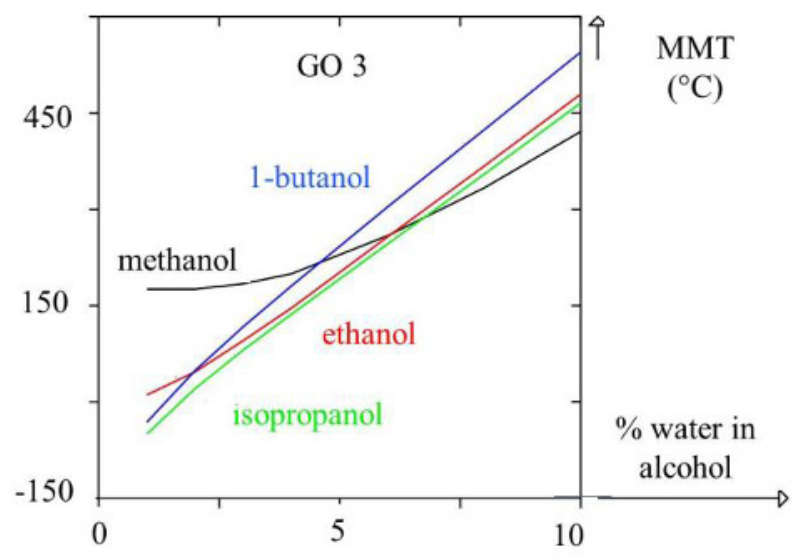

Figure 10. Change of the MMT of the four GO 3/alcohols systems with the water content of the alcohol.
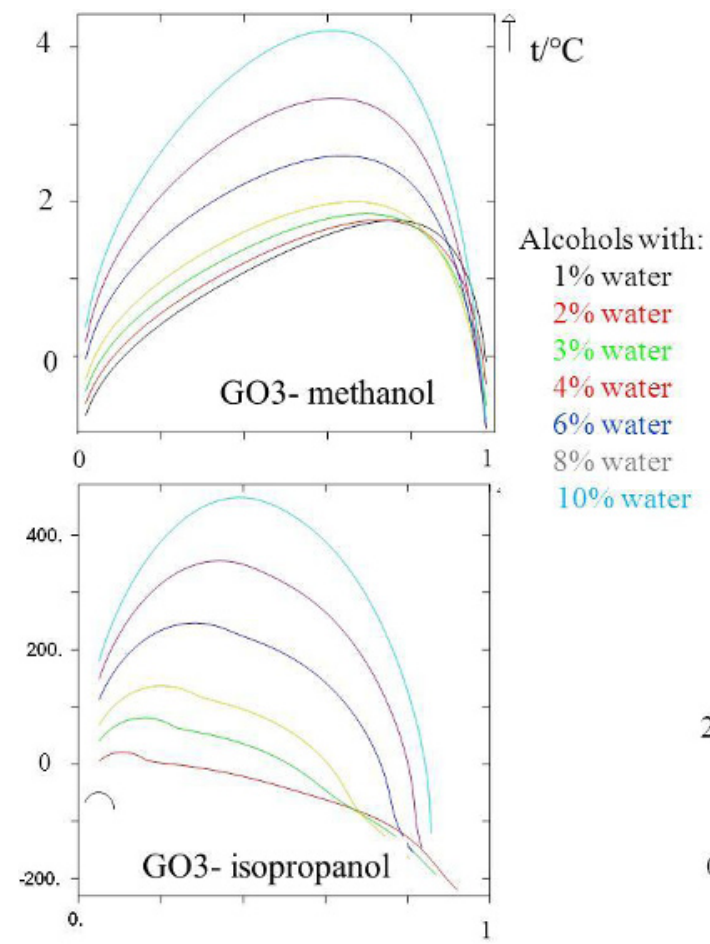

$8 \%$ water

$10 \%$ water
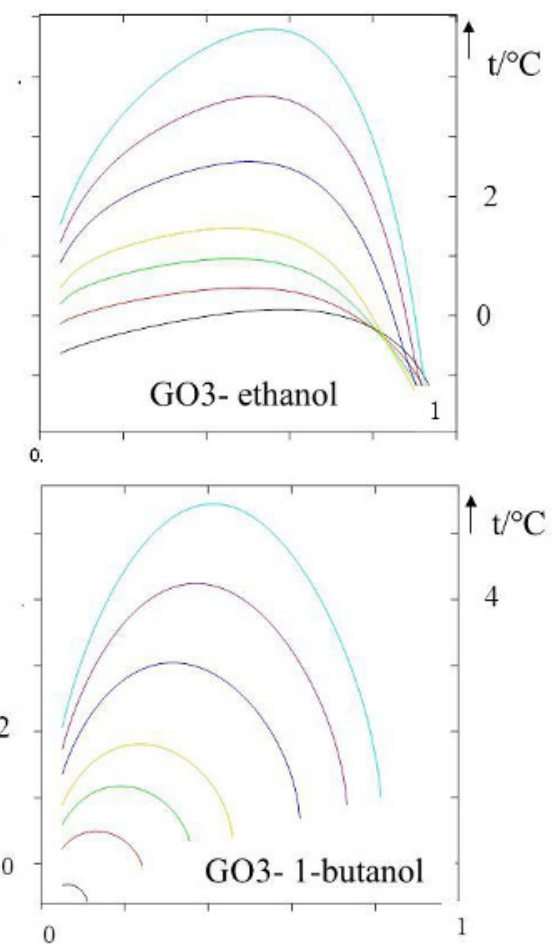

Figure 9. Phase diagrams for GO3 mixed with 4 alcohols containing from 1 to $10 \%$ water (in abscissa: mole fraction of hydrated alcohol).

\subsection{Addition of different industrial alcohols in gasoil GO4}

Phase diagrams can be seen in figures 11 and 12 and the corresponding MMT are given in table 7. Conclusions are
Table 6. MMT values for gasoil GO3 mixed with the four alcohols having various $\mathrm{H} 2 \mathrm{O}$ contents.

\begin{tabular}{|c|c|c|c|c|}
\hline$\% \mathrm{H}_{2} \mathrm{O}$ (mass) & methanol & ethanol & isopropanol & 1 -butanol \\
\hline 1 & 176 & 11 & -50 & -32 \\
\hline 2 & 176 & 47 & 21 & 49 \\
\hline 3 & 184 & 96 & 81 & 117 \\
\hline 4 & 200 & 146 & 137 & 181 \\
\hline 6 & 259 & 258 & 246 & 304 \\
\hline 8 & 334 & 367 & 355 & 424 \\
\hline 10 & 421 & 479 & 466 & 545 \\
\hline
\end{tabular}

Conclusions are the same as with GO1 and GO2. When the water percent goes from 1 to $10 \%$, the MMT (in K) is multiplied by: 1.5 for methanol; 2.6 for the ethanol; 3.3 for isopropanol and 3.4 for 1-butanol. 

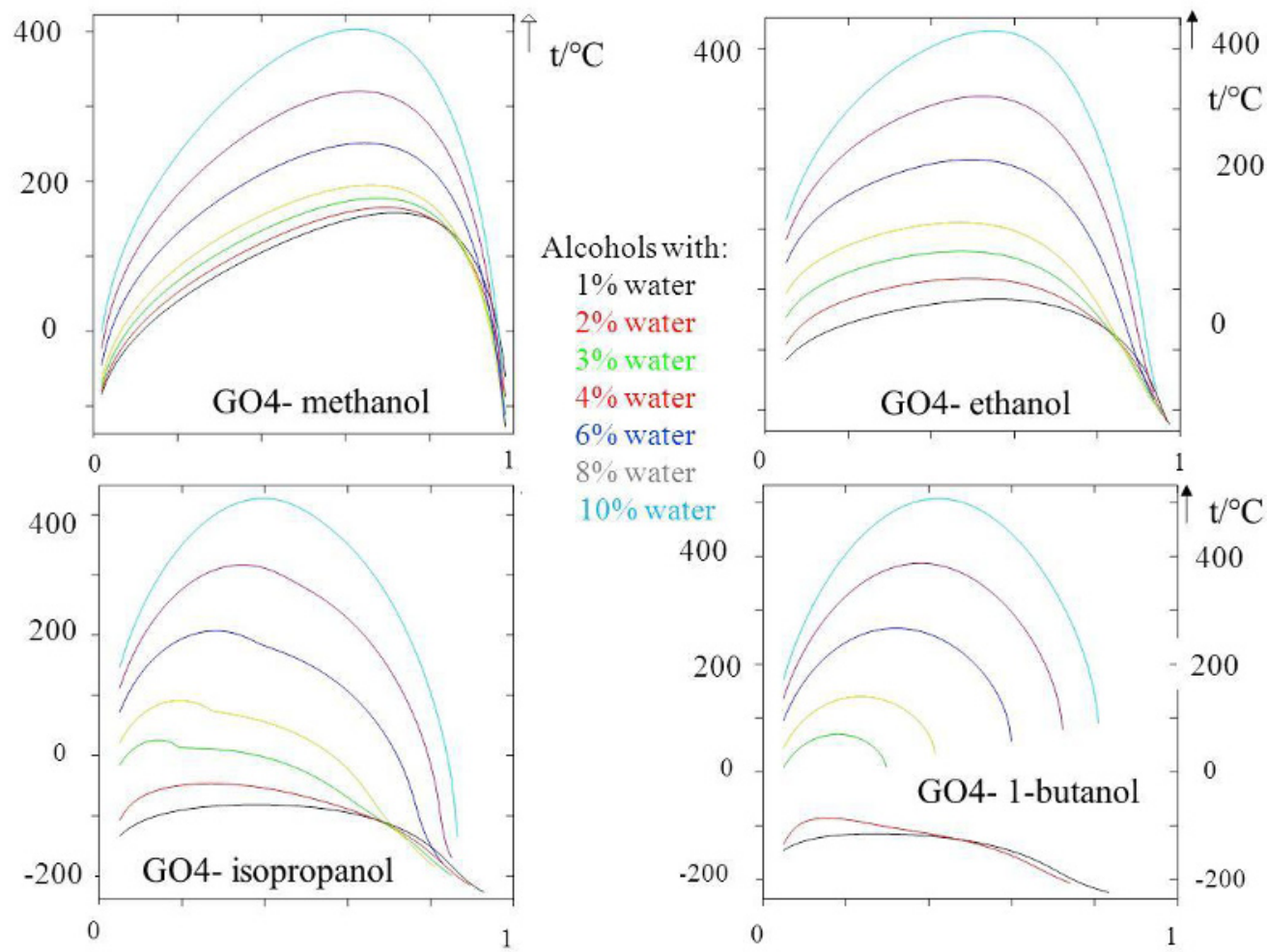

Figure 11. Phase diagrams for GO4 mixed with 4 alcohols containing from 1 to $10 \%$ water (in abscissa: mole fraction of hydrated alcohol).

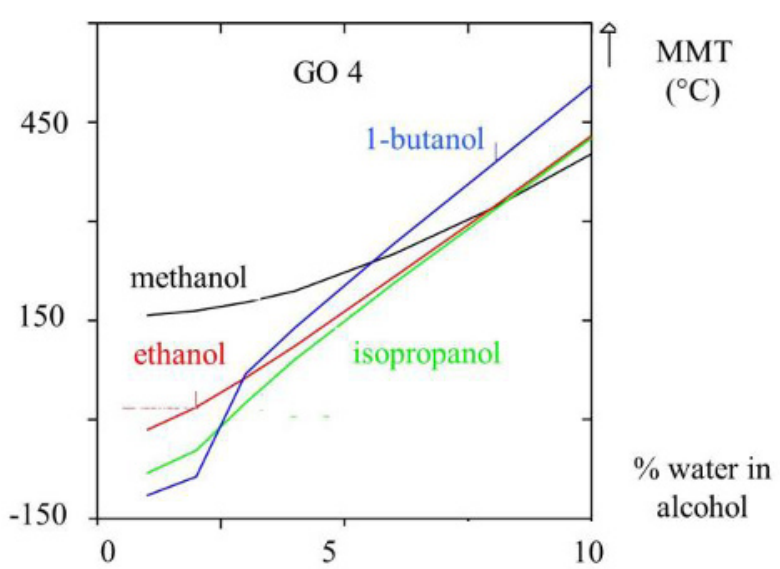

Figure 12. Change of the MMT of the four GO 4/alcohols systems with the water content of the alcohol.

Table 7. MMT values for gasoil GO4 mixed with the four alcohols having various $\mathrm{H} 2 \mathrm{O}$ contents.

\begin{tabular}{|c|c|c|c|c|}
\hline$\% \mathrm{H}_{2} \mathrm{O}$ (mass) & methanol & ethanol & isopropanol & Butanol \\
\hline 1 & 158 & -16 & -81 & -115 \\
\hline 2 & 165 & 19 & -47 & -86 \\
\hline 3 & 177 & 63 & 25 & 69 \\
\hline 4 & 195 & 111 & 91 & 139 \\
\hline 6 & 251 & 216 & 206 & 266 \\
\hline 8 & 320 & 321 & 316 & 386 \\
\hline 10 & 402 & 430 & 426 & 506 \\
\hline
\end{tabular}

\section{7 influence of gasoil composition on the MMT}

From the results above, it is possible to draw the influence of gasoil compositions on the MMT, for a given alcohol. It is remembered that these compositions are summarized in tables 1 and 2. Results are synthesized in figure 13 and are discussed in the conclusion.

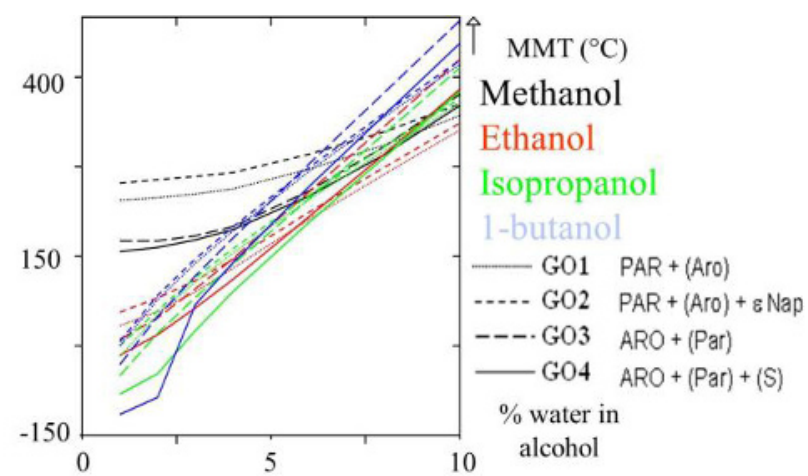

Figure 13. Results summary; Legend:

PAR: paraffins; Aro: aromatics; Nap: naphthenes; S: sulphur; Uppercases: major compounds; in parentheses: minor compounds. 


\section{Conclusion}

This collaborative, multistep study was intended to progress in the thermodynamic description of alcoholhydrocarbons mixtures in presence or absence of water. In a first step, we have pointed out the strongly non-ideal behavior of ethanol-naphtha blends in terms of vapor pressure.

The second step was devoted to providing general guidelines for preparing mixtures of gasoils with industrial alcohols displaying low Minimum Miscibility Temperature (MMT) data. It must be stressed that the MMT values computed in the present paper are sometimes quite high and above the stability temperature of the related alcohols; this points out the essentially theoretical reach of the present study, which owes its main interest to the main trends observed:

1- with slightly hydrated alcohols: it is preferable to use heavy alcohols. As the alcohol molecules gets close, in size, to the hydrocarbons contained in the gasoils, they are better solubilized. It is also preferable to use a gasoil featuring a highly aromatic character and substantial sulphur content in order to prevent any liquid-liquid phase split. Naphthenic compounds should be discarded. The mixtures of 1-butanol with GO4 illustrate well these inferences.

2- with strongly hydrated alcohols: this time, it is preferable to select light alcohols (methanol or ethanol) in order the alcohol molecule size becomes closer to that of the water molecule. Then, water gets more easily solubilized in the alcohol. Here again, it is preferable to take gasoils having substantial aromatic contents and some sulphur containing molecules having more affinity with polar species (water and ethanol) than paraffinic compounds. Once again, naphthenic compounds have to be discarded. The mixtures of ethanol with GO1 illustrate well these inferences.

As next steps, this study will be followed by (i) an experimental work devoted to the verification of these main theoretical results and (ii) a further study of the effect of introducing alkyl esters in the gasoils/hydrated alcohols blends.

\section{Nomenclature}

GO: gasoil

MMT: minimum miscibility temperature.

$\mathrm{x}_{\mathrm{i}}$ : $\quad$ mole fraction of component $\mathrm{i}$ in a given phase.

$\mathrm{z}_{\mathrm{i}}$ : $\quad$ overall mole fraction of component $\mathrm{i}$.

$\gamma_{i}: \quad$ activity coefficient of component $i$.

$\gamma_{i}^{\text {comb }}$ : combinatorial part of the activity coefficient.

$\gamma_{i}^{\text {res }}: \quad$ residual part of the activity coefficient.

$\tau_{\mathrm{k}}$ : molar proportion of liquid phase $\mathrm{k}$.

\section{References}

1. B.E. Poling, J.M. Prausnitz, J.P. O'Connell, The properties of gases and liquids, 5th edition, Mc Graw Hill, 2000.
2. L. Constantinou, R. Gani, AIChE J. 40(10) 1697 (1994)

3. J.N. Jaubert, F. Mutelet, Fluid Phase Equilibria 224 285 (2004)

4. J.N. Jaubert, S. Vitu, F. Mutelet, J.P. Corriou, Fluid Phase Equilibria 237193 (2005)

5. S. Vitu, J.N. Jaubert, F. Mutelet, Fluid Phase Equilibria 2439 (2006)

6. S. Vitu, R. Privat, J.N. Jaubert, F. Mutelet, Journal of Supercritical Fluids 451 (2008)

7. R. Privat, J.N. Jaubert, F. Mutelet, Industrial \& Engineering Chemistry Research 472033 (2008)

8. R. Privat, J.N. Jaubert, F. Mutelet, Industrial \& Engineering Chemistry Research 477483 (2008)

9. R. Privat, J.N. Jaubert, F. Mutelet, Journal of Chemical Thermodynamics 401331 (2008)

10. R. Privat, F. Mutelet, J.N. Jaubert, Industrial \& Engineering Chemistry Research 4710041 (2008)

11. J.N. Jaubert, R. Privat, F. Mutelet, AIChE Journal 56 3225 (2010)

12. R. Privat, J.N. Jaubert, F. Garcia, M. Moliere, Journal of Engineering for Gas Turbines and Power 132 art. no. 091504 (2010)

13. J.N. Jaubert, L. Coniglio, F. Denet, Industrial \& Engineering Chemistry Research 383162 (1999)

14. J.N. Jaubert, L. Coniglio, Industrial \& Engineering Chemistry Research 385011 (1999)

15. J.N. Jaubert, P. Borg, L. Coniglio, D. Barth, Journal of Supercritical Fluids 20145 (2001)

16. R. Gani, P. M. Harper, M. Hostrup, Industrial \& Engineering Chemistry Research 447262 (2005)

17. R. Privat, J.N. Jaubert, Global Journal of Physical Chemistry 1107 (2010)

18. A. Fredenslund, R. L. Jones, J.M. Prausnitz, AIChE Journal 211086 (1975) 